\title{
Process-Oriented Modeling and Analysis of Business Processes using the R/3 Reference Model
}

\author{
Gerhard Keller and Sören Detering \\ SAP AG, Neurottstr. 16, 69190 Walldorf/Baden, Germany \\ gerhard.keller@sap-ag.de, soeren.detering@sap-ag.de
}

\begin{abstract}
In many companies, the business processes of logistics, accounting and human resources are unclear or often even unknown. With the R/3 Reference Model, a tool is available to users that, taking variants (scenario examples) into consideration, clearly portrays business processes of the $R / 3$ system.

The introduction of standard software such as SAP's R/3 makes it possible to reengineer existing processes together with organizational structures. New business solutions are derived from the vast amount of process know-how build into the R/3 System from over 23 years of industry experience.
\end{abstract}

In order to support this introduction, SAP has developed the R/3 Reference Model, a business process model for the processes supported by the R/3 software. It serves as the knowledge base for consultants, managers, and project staff.

The processes are described within the R/3 Reference Model by process, function, data, organization, and interaction views. The R/3 Reference Model covers all R/3 Business Applications including Sales and Distribution, Human Resources, and Finance by depicting overall functionality as well as the integration of the application areas.

The purpose of this paper is to describe SAP's process modeling method, especially the process view, and to delineate the benefits of using the R/3 Reference Model.

\section{Keywords}

Business Process Engineering, Event-driven process chain (EPC), R/3 Reference Model, Service Management, Standard Software

\section{PROBLEM DESCRIPTION}

Worldwide dynamic markets and global competition through multi-national corporations challenge today's corporations. These challenges represent new business opportunities. New business concepts are being sought, which enable the corporation to quickly and efficiently satisfy customer needs within competitive markets. Such a concept needs to address:

- short product-cycles,

- dynamic adjustments of production,

- and efficient logistics.

To achieve this, business processes have to be reengineered and supported by a company-wide Information System. Such a system should be constructed taking into consideration existing industry standards. 
In recent years, "Business Process Reengineering" (BPR) has become an important method for the restructuring of organizations. The goals of a BPR-project are optimized organizational structures and processes, as well as new applied technology. SAP, a global player in the client/server application software market, utilizes its integrated R/3 software to support both goals of BPR through the creation of open client/server architectures and flexible new designs.

As many companies get ready to implement standard software, they encounter the problem of how to simplify and model the enormous complexity of their business processes. Often, they conduct timeconsuming and costly preliminary project reviews in an attempt to develop a target concept. The questions that crop up are essentially the same in all cases:

How can a company model and reorganize its business processes when implementing R/3?

- Can a company perform its business processes with the $R / 3$ system? Or, to put it another way, can the predefined reference processes of the $R / 3$ system meet the company's requirements?

The R/3 Reference Model was developed to assist customers in this quest to find the optimal business process solutions.

\section{PRINCIPLES OF BUSINESS PROCESS DESIGN}

Business process design encompasses a variety of different buzzwords in practice today, including Business Process Reengineering, Continuous Engineering, Process Innovation, Change Management, Business Transformation, etc. (see Andrews, C. D./Stalick, S. K. 1994; Davenport 1993; Doppler, K./ Lauterburg, C. 1994; Hammer 1993; Towers 1994). On the other hand, it is also being discussed as a scientific theory in such publications as Organization Theory, Business based Computer Science and Computer Science.

\subsection{Today's Practical Discussion}

When looking at the possible business process offered by a potential data-processing supported information system, a huge danger lurks. The number of processes and their variants are theoretically infinite. There also has to be a way of freely varying the details of business processes in response to different, and changing, market requirements.

Each company wants to shape its processes to optimally suit the „market segment,“ „,customer group,“ or "product line“ in question - and rightfully so. From the standpoint of users, it would indeed be a big mistake to mistake these business processes as something absolute and then proceed to individually and indelibly - program the details of each one. If a process should then ever need to be changed, an everyday event with modern organizational structures, a company would be up the proverbial creek without a paddle. It would have once again fallen into the trap already charted a decade or so ago by so-called ,industry systems.“

The reason is that „optimum support for one or a few selected processes of a branch industry“ - the details of which have been written right into the program code - may indeed serve momentary needs very well. But if the business changes, companies find themselves straitjacketed by their „own“ routines, incapable of integrating new processes.

The only way to overcome this dilemma is with integrated IT systems designed along modern, flexible business lines. Besides the benefits offered by relational databases, client/server architectures (see Plattner 1993; Kagermann 1993a; Kagermann 1993b; Buck-Emden/Galimow 1995) and the 
availability of open Business Application Programming Interfaces (BAPIs) for tying in „third-party“ products, such systems include central „business objects.“

Like „order,“ „goods receipt" or „financial accounting document," these can assume different guises and attributes within the architecture of R/3. Depending on the context, for example, an order in the $\mathrm{R} / 3$ system can take many forms: that of a "standard order," a "delivery schedule," or an "outline agreement." It can refer to a „purchase requisition" or be ,,assigned to an account.“

Parameterization of such business objects, which are entity types in their own rights, makes it possible to use the same system to model quite different business processes. The internal architecture of $R / 3$ is such that the most important business objects are encapsulated along with the required methods. They can also be freely invoked, permitting their context-sensitive integration at any point along a customer's business process chain (see Keller 1995a; Zencke 1994).

\subsection{Today's Theoretical Discussion}

When a company is analyzed for the purpose of identifying possibilities for optimizing how their routines and procedures are organized, the same three basic design principles are always relevant:

A task or function describes ,what should be done."

An organization describes ,who should do something.“

An information object describes ,which information is needed to perform a function.“

From a historical perspective, the first issue that companies focused on was design of organizational units. Starting early in the 1920 s, a great deal of attention was devoted to this aspect by both theoreticians and practical businessmen (see Nordsieck 1932). With the advent and spread of data processing, functional aspects gained high attention in the early 1970s. Finally, with the emergence of integrated databases at the beginning of the 1980s many companies turned their attention to structuring of data. Looking at the methods that are now available with the declared aim of making companies and information systems more transparent, analogies can be readily drawn with the past requirements of companies over the decades. Today a vast number of methods with different focuses exist (see Keller 1993, p. 43-105).

So many methods are now available (see Scheer 1992), some of which only differ minimally from one another, that it has meanwhile become extremely difficult to see the woods for the trees. The resulting confusion has prevented the emergence of a standard concept for development of application software.

In general, it can be stated that the existing methods either fail to give adequate attention to aspects related to the organization of processes or else are so complicated that it is not always possible to comprehend the intricacies of the resulting process logic. In the years to come, control logic - in other words, "when should something be done“ - is set to play a central role in connection with optimization of business processes. One reason is that it is intimately bound up with organizational design, specifying what should be done by whom, how and when. Also, it possesses immense importance for the planning of IT concepts whenever triggers or messages are used to determine which transactions should be executed by whom and when. If the aim is to support business processes by ensuring optimal interplay of staff and information technology, then a method for graphical description must be found that can be used to clearly model business processes. 


\subsection{The R/3 Reference Model}

Any examination of the current discussion concerning the formation and planning of information systems reveals that the emphasis even today remains on the construction of architectures and tools. In the 1980s, the focus was on the general description of information systems, but since the start of the current decade, business processes have increasingly taken center stage. Projects concerned with the construction and creation of application architectures include AD/Cycle (Application Development), ARIS (Architecture of integrated Information Systems), ASEM (ATMOSPHERE System Engineering Model), BOS Engineering Method, CC RIM reference model, CIMOSA (Open System Architecture for CIM), ESF (Eureka Software Factory), GERAM (Generic Enterprise Reference Architecture and Methodology), IEM (Information Engineering Method), IRDS (Information Resource Dictionary System), ISM (Information Systems Methodology), PERA (Purdue Enterprise Reference Architecture), and SOM (Semantic Object Model) (see bibliography by Bernus/Nemes 1996, Nüttgens 1995, p. 18-68; Dürmeyer 1993; Ferstl/Sinz 1990 and 1994; Kosanke 1993, Williams 1996). In contrast, the R/3 Reference Model was not developed with a view to the creation of an information system, but is intended to clarify the business solutions of the R/3 system in simple model screens.

The initial aim was to create an easy-to-understand description of the business processes contained in the R/3 System to supplement the existing descriptions of R/3 information objects (entity types) in the SAP data models. What we had to work with were the data models of the individual areas, plus knowledge of the structural relationships among the system organizational units of the R/3 System. Based on the results of preceding research, two main goals were defined at the beginning of the project.

- Customer orientation

As a basic principle, reference models can be created for different target groups. Whereas, to put things simply, a software developer wants to see every single detail, from the point of view of final users and organizational planners it can actually be harmful to be confronted with an excess of detailed information during the first stage. The aim was therefore to select a method for description that is simple (i.e. using a small number of different symbols), clear (i.e. using a particular arrangement of the symbols), and nevertheless unambiguous (i.e. must be possible for a layperson to immediately understand and grasp a depicted process structure). The EPC method was conceived for this purpose.

- Model orientation

What models do is abstract real-world phenomena. However, a balance needs to be struck between information content and comprehensibility. Considering the complexity that is now typical of corporate structures, particularly in the case of internationally active companies, it is immediately apparent that the straightforward but naive approach of modeling all possible situations would soon get bogged down in an impenetrable thicket of application and models. This also applies to the modeling of computerized information systems. If one were to completely model all possible combinations that can be configured in R/3 within the scope of customizing, then the model would be complete, but in terms of information content it is more than users can cope with. Because of this, the R/3 Reference Model describes the business processes that are most commonly needed in practice along with their variants, thus ensuring that these can actually be implemented with $R / 3$. Whether or not there is any point in modeling other alternatives must be checked from case to case within the scope of customizing. 


\subsection{1 „Event-driven Process Chain“ (EPC) - The basis for business process and organization design}

Based on the discussions taking place in the area of organization and information system planning, SAP developed, in cooperation with a research institution, the Event-driven Process Chain (EPC) as a way to portray business processes (see Keller et al. 1992; Keller/Meinhardt 1994a; Keller 1995a; Keller 1995b).

Basically, EPCs are made up of active components that do things (functions) and passive components that only come into play in response to certain business situations. It should be stressed that not every business situation is also an event. What characterizes an event is its ability to trigger one or more functions when it occurs.

Practical experience has demonstrated that even complex business processes (e.g. with a great many branches and parallel flows) can be very quickly modeled with the aid of EPCs by users not familiar with the internal programming logic of a DP system. It is important, however, to avoid the common mistake of using Event-driven Process Chains to model the flow of information (i.e. which data is exchanged between functions). Presumably, such mistakes stem from companies that for decades were used to looking at functions in terms of the associated information flows. In order to describe business process logic (control flows), it is of overriding importance to find the „right events, “ which is by no means always a trivial task.

For example, in the example shown below, the event ,goods arrived“ triggers the function „check goods." Within this function, it is ascertained whether or not the supplied goods are identical with the ordered items and whether the shipment is complete. The "result event" of this function could now be modeled as „goods checked.“ However, closer scrutiny of the process reveals that this approach is faulty. If correctly modeled, the function ,check goods“ yields the event „goods released“ or „goods blocked“" or „goods rejected.“

In the first case, the delivered goods can be immediately passed to production or the consignment warehouse for further processing. If the goods are incomplete because some wrong parts are delivered, then it may be necessary to hold them back temporarily or to send them back to the supplier immediately. 


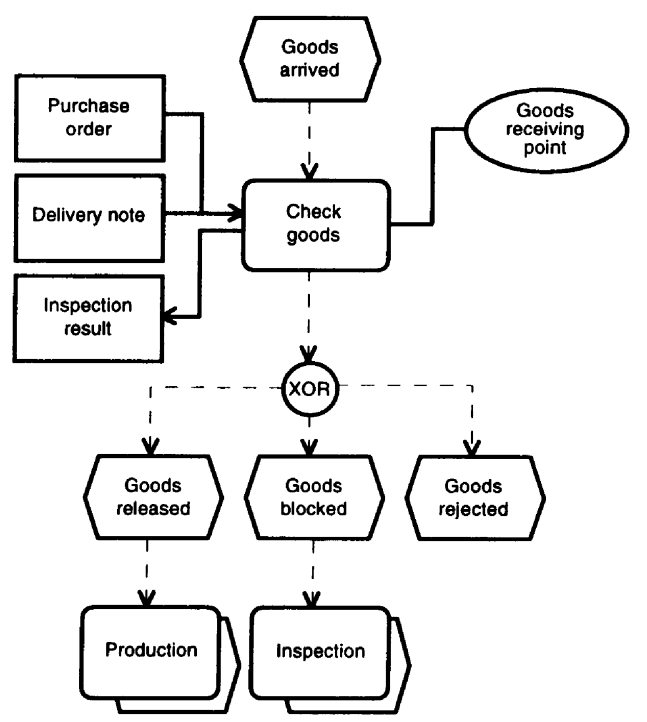

Figure 1 Example of an Event-driven Process Chain (EPC).

By connecting events and functions with logical operators, even very complex business processes can be transparently modeled. In addition to depicting the process structure as control flows, depending on what is involved, the information received or generated by a function may also be important for analysis of an enterprise. In the case of ,check goods, “ an order and delivery note are needed in order to perform the check; and the information generated by the function as the result of the check may be required by the purchasing department for evaluating the supplier. Because the pieces of information represented by „purchase order,“ „delivery note“ and ,inspection result" do not have character control, they are simply assigned to a function as input or output and can be taken as the basis for compiling an information flow diagram.

In addition to analyzing points where information must be transferred from one medium to another, breaks in the chain of tasks and responsibilities necessitated by transfers between organizational units have an especially great bearing on optimization of processes because they often cause unacceptably long delays. By lining up organizational units with the individual functions of an EPC, it quickly becomes apparent just which departments are involved in a given process.

Navigation between individual process models is performed with the aid of initial and final events. However, in the case of paper printouts, there is no longer a directly visible connection between different processes. Because of this, ,process paths“ have been introduced. Such a process path indicates either the previous process or the next process to be branched to. For example, the process "check goods“ results in the final event „goods released.“ This final event also contains a pointer to the process ,production.“ The event ,goods released“ is simultaneously the initial event of the process „production." This initial event also points back to the process from where it originated. However, in order for the process ,production“ to start, the event "production date“ must have also occurred. Pointers make the logical connection to the $\mathrm{R} / 3$ system on a case-by-case basis, providing links to the appropriate application transactions and the R/3 application documentation.

With the EPC, it is possible to see different features (attributes) like, for example, processing time, changes in processing, the amount of support, etc. The different important factors of a given business process attribute lead to the customer confronting the problem of information overload - when the complete description of processes is included. Because of this, strategies for portraying processes can 
be traced with the EPC method. If the customer wants to analyze business processes and all of their variants, independent of organizational restrictions, it is recommended to look at control flows with events, functions and linking operators (and eventually process paths) with the „lean EPC.“ To handle organization questions, organizational entities should be modeled (for example, from an analysis of workflow). If object flow is also to be analyzed, the input and output of information objects must be included. This leads to two diagrams, the „lean EPC“ and the „EPC Assignment Diagram.“

Business process design projects can be started from different points and settings (organization analysis, application area analysis, business process analysis). Independent of the three basic principles discussed above, it is important to get an overview of the „business (process) field“ before looking at the detailed design of business processes. First, the software vendor must understand the business area and business requirements of the customer. On the other hand, the customer must have a clear picture of the main business processes that the software system can support.

For this, a „process selection matrix" was conceived to name and classify business processes. First, the so-called "main processes" are listed in the left column, indicating they're a part of the application area. However, the „main processes" of other application areas are also listed here, connecting the applications even more. For example, in the process selection matrix, Sales and Distribution includes the process of ,product costing," which is also listed under the area Controlling. Depending on business demand, the main processes can also have variants. These would be listed under the heading „scenario." However, in different applications, different criteria for designing scenarios are relevant. For example, the heading under sales might be „order type,“ in Materials Management „open production order type," and in Controlling ,accounting rules“. The goal is that the customer can organize the process selection matrix by hand and establish the analyzed business processes. Selecting business processes from the process selection matrix is the first step in getting an overview of the scenarios in the EPC. Here, the target processes that cross application boundaries can be defined. Putting the logical structure, with each individual "process building block, " on the different scenario levels frees up the basic elements of the affected applications and lets users look at the relevant organization and information details through the EPC. 


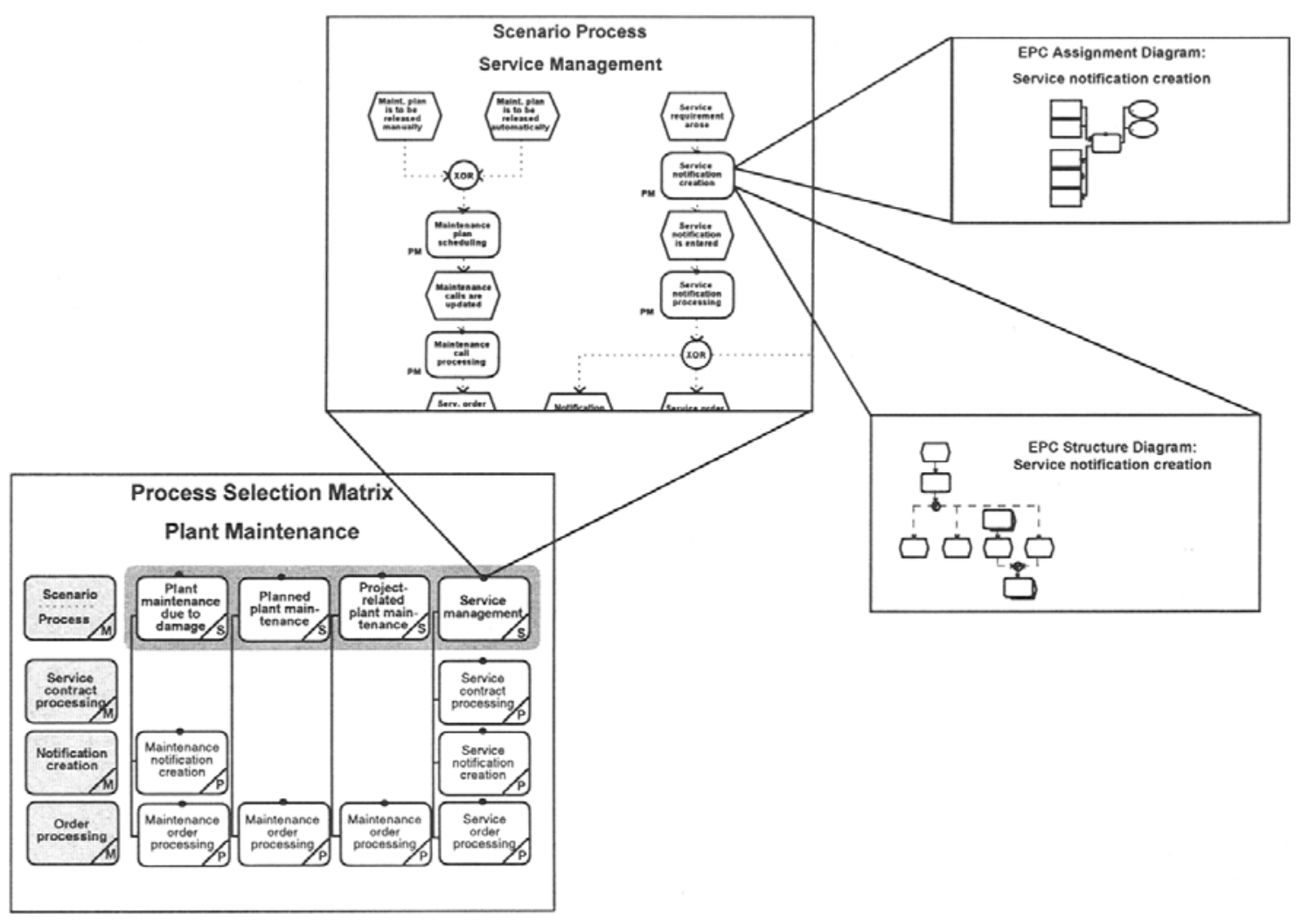

Figure 2 Conceptual navigation in the R/3 reference process model.

The process selection matrix allows Reference Model users to get into the process models of $R / 3$ and answers questions about the characteristics of each business process and its logical time sequence inside of the defined scenario. By selecting (for example, highlighting paper print-outs of the matrix with colored markers during an internal workshop) a process from the process selection matrix and placing EPCs in the right scenario levels, users can quickly and consistently check the determining factors of their business process design.

\subsubsection{Structure-oriented Views}

In addition to looking at business processes, other factors can be of interest during the planning of business and information processing concepts. The following questions are essential to reference modeling (see Keller/Meinhardt 1994b; Keller/Popp 1995):

- What information is needed to make a company more efficient and how can an information system support it?

- What connections exist between task or function areas and application areas and how can the exchange of information through different user applications be supported?

- Which tasks or functions are carried out within goods and services and what business functionality does the application software support?

- Which organizational entities are responsible for carrying out tasks and how can they be portrayed by an information system? 
It is possible to answer these questions using the EPC method to illustrate processes from different viewpoints. These viewpoints are represented in the Data View, Function View, Organization View, Information Flow View, and Communication View (see following Figure).

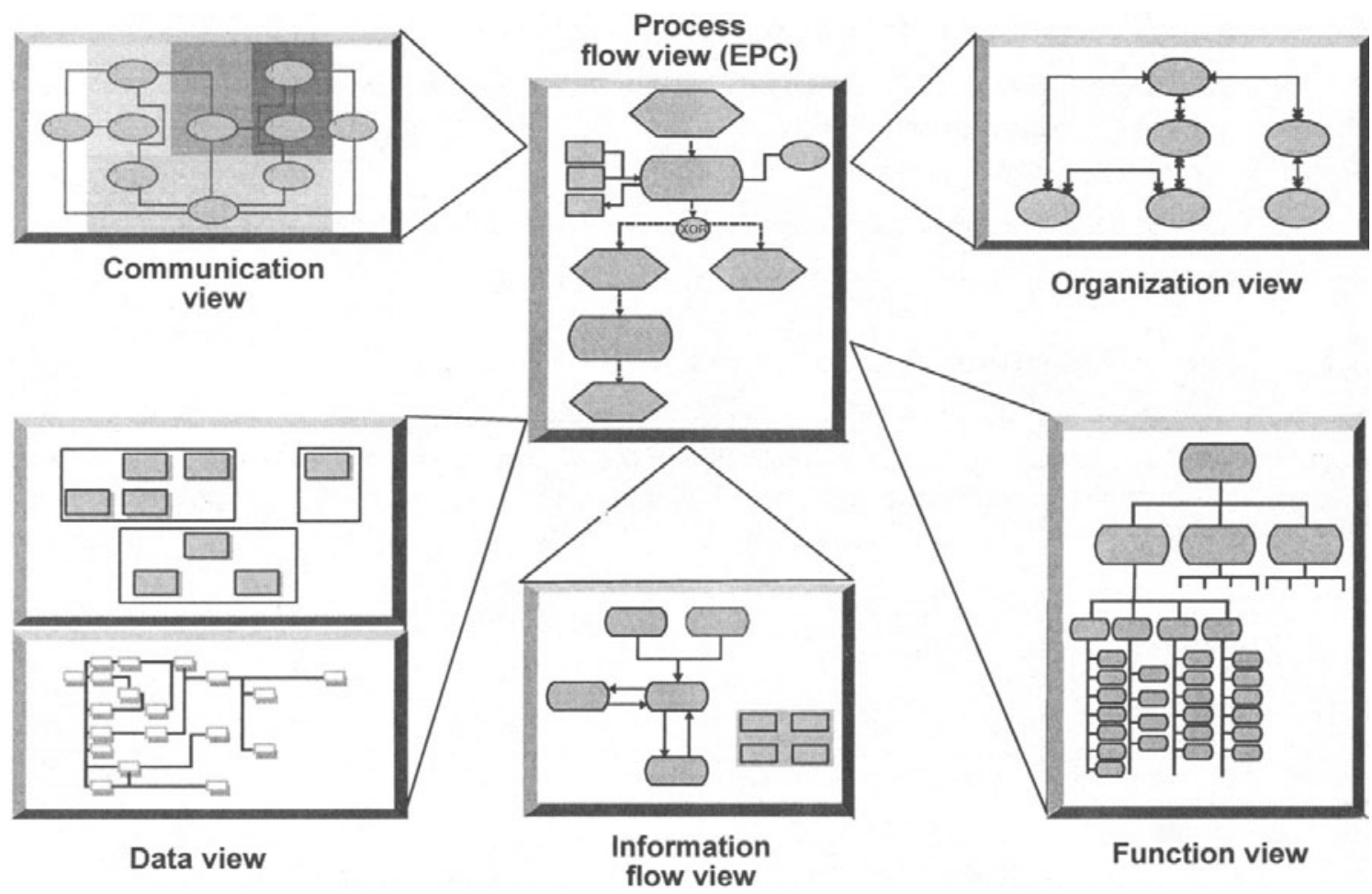

Figure 3 Views of the R/3 Reference Model.

\section{BUSINESS PROCESS MODELS IN PLANT MAINTENANCE AND SERVICE MANAGEMENT}

The following section is a description of the Service Management (SM) models within the Plant Maintenance (PM). It serves as an illustration of the methodology described in the previous sections.

The PM System provides solutions for the management and maintenance of technical systems in all branches of industry. It can manage both internal company systems, such as production, procurement, disposal and transport systems, and third party systems such as customer equipment (as covered by SM).

Carrying out maintenance activities as a service is becoming increasingly important. Strategic corporate objectives, e.g. close and long-term customer relations can be reached through enhanced customer service. Lower margins in sales, a profitable business on spare parts, and stricter regulations regarding manufacturer liability increase this trend. 
Therefore, information on pieces of equipment purchased and tasks performed on them has to be readily accessible. In the R/3 System, this goal is reached through PM/SM and its integration into the logistics and accounting systems.

The business processes of SM are depicted by the following models:

- Process Selection Matrix for Plant Maintenance (including Service Management)

- Scenario Service Management (Part)

- EPC „Service notification creation“

- EPC Structure Diagram ,Service notification creation“

EPC Assignment Diagram „Service notification creation“

\subsection{Process Selection Matrix for Plant Maintenance}

The Process Selection Matrix lists all master processes of the PM application in the first column. Business process variants are shown as scenarios in the top row of the matrix (see Figure 4). The scenarios are „Planned plant maintenance,"1 „Plant maintenance due to damage,“2 „Project related plant maintenance, $" 3$ and „Service Management"4.

${ }^{1}$ One of the main functions of maintenance is to ensure a high level of availability of the production systems in the long term. Preventive maintenance is the ideal way to avoid system breakdowns, which in addition to the basic repair costs often incur far higher subsequent costs as a result of the loss in production.

2 Malfunctions or other exceptional situations require prompt action on the part of the maintenance organization. To deal with these, the PM System contains a comprehensive notification system for creating and managing company notifications.

${ }^{3}$ Large maintenance activities are planned as projects. Work orders integrated with the project system (PS) are assigned to networks.

4 Planning and controlling the main activities of service and maintenance at the customer site is the focus of Service Management, which will be shown in more detail in the scenario (see section 3.2). 


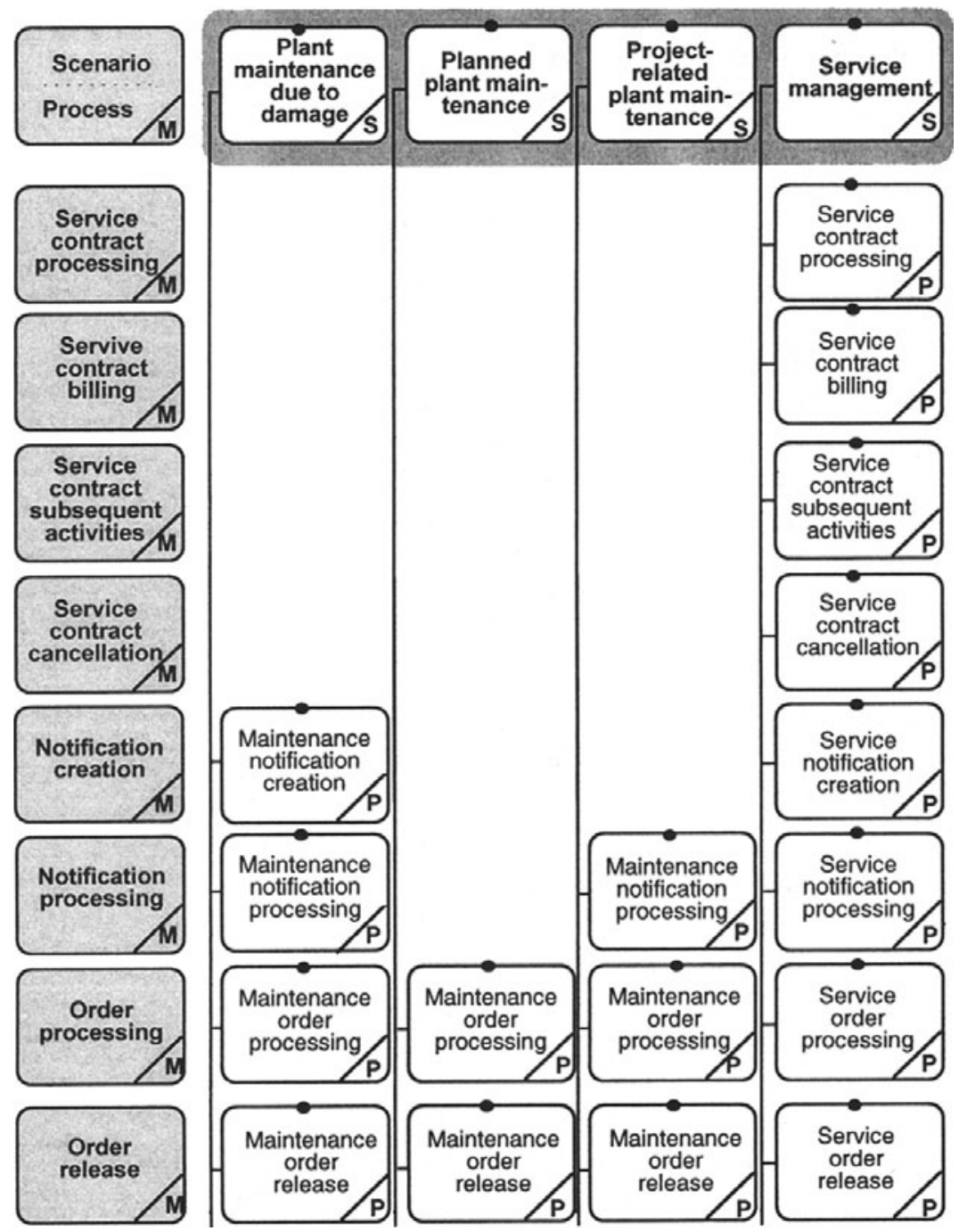

Figure 4 Process Selection Matrix Plant Maintenance (Part).

Processes relevant to Service Management, e.g. „Service contract processing,“ are listed below the scenario header. Process-variances become visible in the area of the notification and the order: Within „Plant maintenance due to damage" the notification is processed through „Maintenance notification processing," whereas within "Service Management" it is processed through „Service notification processing."

\subsection{Scenario Service Management}

Service Management is a good example of the integration of business applications shown by the $R / 3$ Reference Model. The scenario consists of processes from Materials Management (MM), Sales and Distribution (SD), Plant Maintenance (PM), and Controlling (CO). A reference to the application is given in the lower left corner of each function-symbol in Figure 5 .

Central tasks of Service Management are: 
- The sale of a piece of equipment,

- subsequent service contract creation, and

- service call and service order management.

In this example, only the third task is described (see Figure 5).

Call management extends from the time the customer initially logs the call, through service planning and procurement of the necessary resources, until call completion and billing. Out of these stages, three can be found in Figure 5, which represents the beginning of the Service Management scenario:

- Service Call Logging (box a)

Service notifications are used to request the necessary service and maintenance activities. This is modeled with the event "Service requirement arose" which triggers the process "Service notification creation.” The process „Service notification creation“ is detailed below.

- Service Call Handling (box b)

The event "Service notification is entered" triggers the process "Service notification processing". In this process, a decision is taken how to resolve the service call. It leads to three possible alternatives:

1. If the problem can be solved by phone, the call and thus the service notification itself are completed at this time. In this case the service activity consists of a consultation and is represented in the system as a notification.

2. If there is a need to record the work of the service technician and the resources used in more detail, a service order is generated through the event "Service order should be created." This allows detailed planning of the execution of the service activities, estimation of the costs incurred, and tracking of the progress of the order.

3. If components or spare parts are required by the service, this is represented in the system using a standard customer order (Figure 5, box b').

- Service Order Planning (box c)

However, if a service contract exists, periodic service specified by the relevant contract can be triggered by the event-function sequence seen on the left hand side of Figure 5 (box c). This sequence models the scheduling of maintenance plans as well as the creation of service orders based upon these plans.

Each function symbol of this scenario points to another EPC Structure and Assignment Diagram, which shows the corresponding process of Service Management on a more specific level. One example for a detailed process is given next for the "Service notification creation“ process (see section 3.3). 


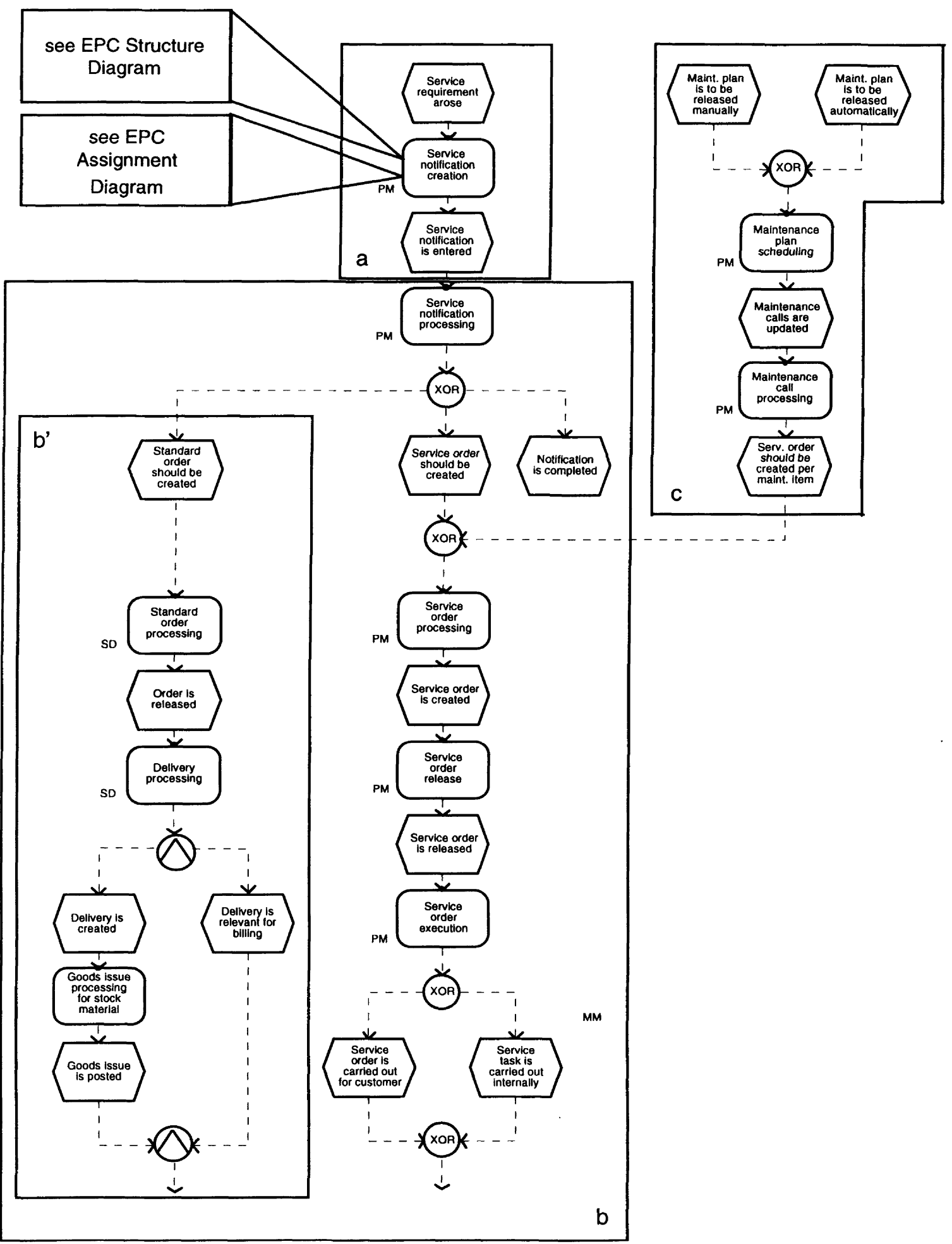

Figure 5 Scenario „Service Management“ (part). 


\subsection{EPC „Service notification creation“"}

\subsubsection{EPC Structure Diagram}

A maintenance notification describes a technical state of exception in a piece of equipment (reference object). Service notifications are used to request the necessary service and maintenance activities. They describe the status of the service objects and track the progress in resolving the problems. At the time a service notification is created, the service object is specified as well as the problem or the requested service, the due date, and the responsible person at the customer site (see Figure 6). The notification is then saved to be processed through „Service notification processing.“

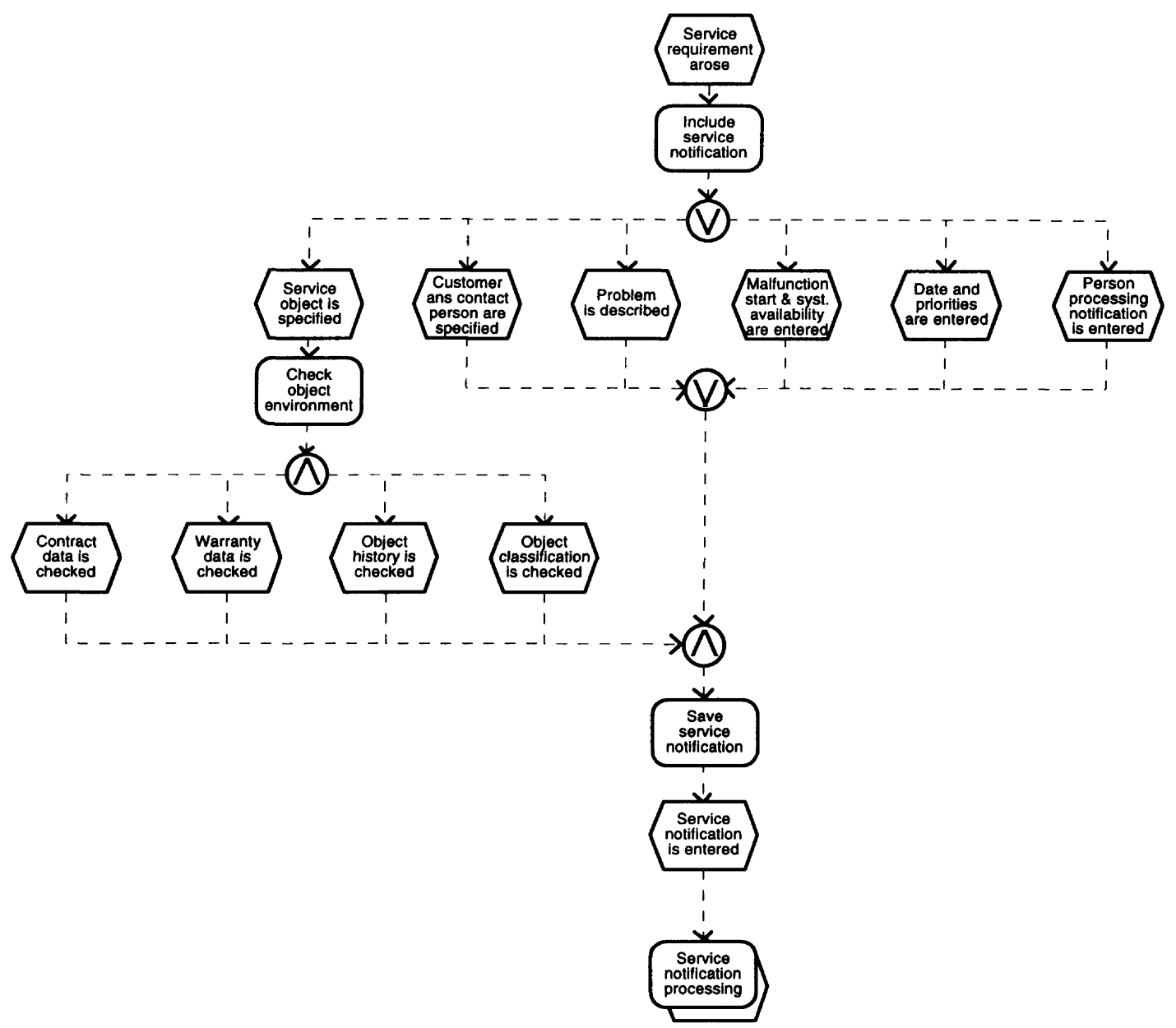

Figure 6 EPC Structure Diagram „Service notification creation“. 


\subsubsection{EPC Assignment Diagram}

To create a service notification, the required input information objects are the „Equipment," the "Customer,“ the „Service material,“ and the „Service contract.“" Through the performance of the „Service notification creation“ process output information objects „Service notification“ and „Service order" are created. System organizational unit types involved in this process are the "Sales area" which created the service contract for the piece of equipment, the "Service planning group" which plans the tasks for this notification and the "Service plant" which performs the maintenance tasks (please refer to the following Figure).

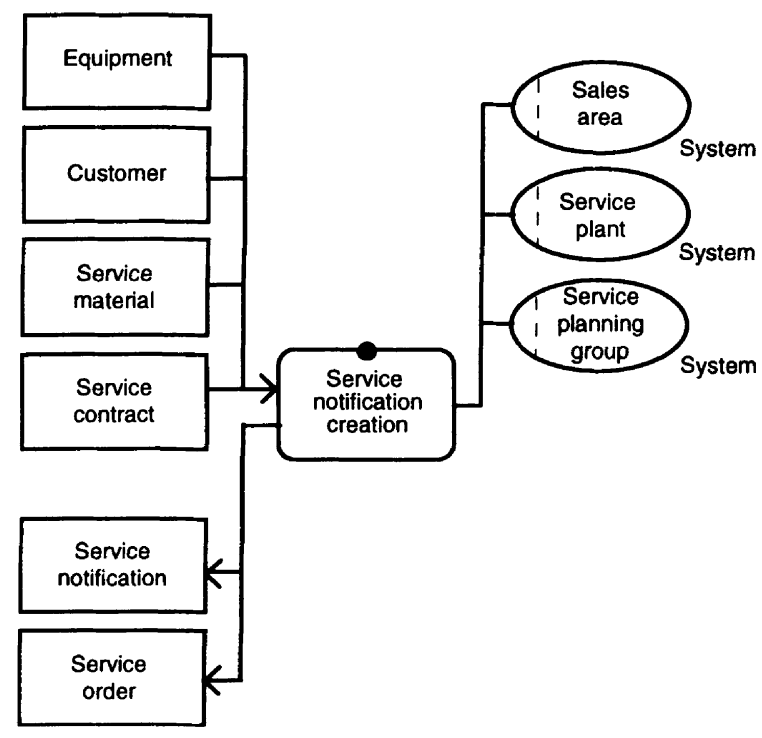

Figure 7 EPC Assignment Diagram „Service notification creation“.

\section{BENEFITS OF THE R/3 REFERENCE MODEL}

Benefits of using the R/3 Reference Model are described by the following project-related tasks:

- Documentation

Documentation is an integral part of process management. Its contents provide information concerning processes, data, and functions. One problem, particularly common in the area of groupware and workflow applications, is that process events are distributed over time and space (see Detering 1995; Pentland 1992). Processes typically require days and weeks until completion and often involve multiple companies. For this reason, it is difficult to analyze the current situation as well as the target situation. To make matters worse, project participants often use differing terminology not necessarily understood by all project members. While using the R/3 Reference Model, project staff develops a common terminology, incorporating SAP terminology. Customer specific language can easily be mapped into SAP specific language.

- Project Implementation

Use of the R/3 Reference Model within implementation projects provides several advantages (see Meinhardt 1995b):

Project members and management work with the same terminology. 
O Notational consistency due to modeling the complete R/3 System using the same method. Customer processes modeled with the EPC can thus be compared easily, seamlessly integrating different views of the R/3 Reference Model together in one tool.

O Models are integrated with other tools like the $R / 3$ Documentation and the transactions of $\mathrm{R} / 3$. Navigation from the EPC to the Data Model leads directly to the underlying tables, table fields and table contents of $R / 3$, the implementation level.

Use and reuse of the models at different times during a given project provides invaluable project structure.

Implementation time of standard software is reduced significantly through method and tool support.

\section{- Requirement Analysis}

Within the requirements analysis cross functional working groups define the relevant processes to be implemented by the information system. The project can be organized using a matrix organization: process responsibilities can be assigned to individuals or groups with the aim to optimize the representation of relevant business processes according to their requirements. The $\mathrm{R} / 3$ Reference Model facilitates comparison between requirements and $R / 3$ functionality.

\section{- Design of a Target Concept}

The target concept describes, how a company's business processes are supported by the R/3 system and the structure of the organization. In parallel, the R/3 Reference Model is used to describe the target concept while a prototype is developed in the R/3 System to validate the conception and solution. On model level business relationships of processes together with their control flow and organizational responsibilities are described. Company specific details can be derived by iterative prototyping, study of $R / 3$ Documentation and customizing the transactions of the business processes.

Significant changes between the future and the current situation and the organizational responsibilities per business process are documented. This documentation reflects the removal of existing weaknesses while supporting management decisions. Decision and subsequent implementation of organizational changes takes considerable time because everyone effected by the change needs to be convinced of the benefits (see Meinhardt 1995a).

\section{- Train Users}

A process-oriented training concept is needed for both SAP consultants and SAP customers. Therefore, a training concept is currently being developed based on the R/3 Reference Model. In constructing this training concept, several media are being employed. The following describes this training program. The tutor leads the student through the training using a script. The script is based on selected processes of the R/3 Reference Model which contribute to better understand the process know-how. The correlation between real-world business examples and the software representation is made clear using selected processes on paper and within the system. Screencams show video taped sessions covering the discussed material. The student gets handson experience in porting these process examples - the process know-how - to the live R/3 System.

- Continuous Improvement

While BPR-Projects are usually only one time projects, the customer's business processes need to be improved continually. Standard software supports continuous improvement efforts through its flexibility and future software enhancements. The customer process models represent a dynamic documentation capable of incorporating changed and new processes. Suppose for example, that a legal aspect concerning the production process has been changed. Industrial 
engineers identify the appropriate process, change it or add a new subprocess to the customer model, and implement the resulting changes to the system.

\section{OUTLOOK}

Business process reengineering, a buzzword in the current debate on management theory, has already become solidly established in corporate practice. But there are still too few broadly applicable, concrete strategies for bridging the gap between concepts and real companies. There are several reasons for this (see Popp 1995):

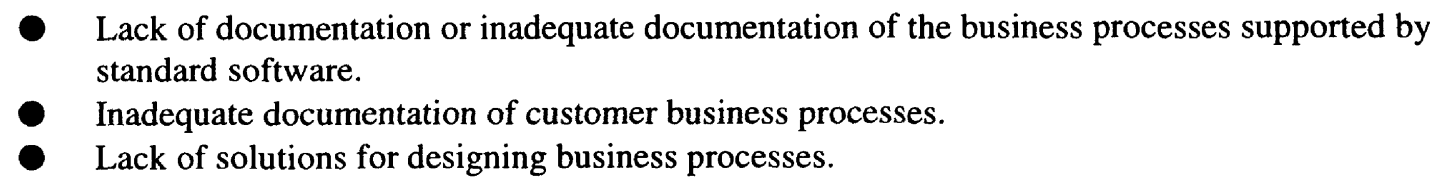

- Lack of documentation or inadequate documentation of the business processes supported by standard software.
- Inadequate documentation of customer business processes.
- Lack of solutions for designing business processes.

Different strategies exist for defining business processes and implementing them in IT systems. One is to work with consultants to design ,ideal“ business processes as the starting point. However, this approach places high conceptual demands on everyone involved and calls for very sophisticated modeling tools. It is also typically cost-intensive and time-consuming, running counter to the widespread wish to cut implementation costs. Another, and probably better, strategy is to begin by regarding reference models as an intelligent knowledge base of solutions, enabling decision-makers to reduce their risks. The additional latitude companies gain from this, of course, would be simproved if all software vendors were to come right out and reveal the business process variants their systems are able to support.

SAP AG has flexibly designed the architecture of its $R / 3$ system to enable the greatest possible range of business processes in different industries. The R/3 Reference Model depicts possible variants in the form of business process components, implemented as Event-driven Process Chains. Users can also combine these components with one another to tailor added value chains to their particular needs. SAP has updated and extended the reference processes in Release 3.0, increasing the number of business process components to more than 800 , e.g. customer quotation processing, standard order 1 processing, delivery processing, invoice processing, purchase requisition processing for stock materials, purchase order processing for stock materials, goods receipt processing, etc. In addition, more than 60 example profiles (scenarios) have been created for a wide range of corporate activities, demonstrating different combinations of business process components.

The previously released Reference Model of Release 2.2, a component of the „R/3 Analyzer,“ has already helped more than 700 customers worldwide implement SAP software. They belong to a wide range of industries, including chemicals, metalworking, steel, mechanical engineering, automotive, office and computing equipment, electrical goods, precision mechanics, optical devices, wood, paper, printing, food and tobacco, retail and services. In the beginning, mainly large companies and management consultants used the Reference Model. But now there is a trend towards small- and medium-sized companies, which also want to take advantage of this information source.

SAP AG's authorized reference processes were previously only available on the laptop tool, the „R/3 Analyzer," but Release 3.0 now also makes these graphical models available in the R/3 system itself within the „Business Navigator" tool. For the first time, users can now navigate from reference processes to the corresponding objects of the data model and directly invoke R/3 transactions from within the reference processes. 


\section{REFERENCES}

Andrews C. D.; Stalick, S. K.: Business Reengineering - The Survival Guide. Englewood Cliffs 1994.

Bernus, P.; Nemes, L.: Enterprise Integration - Engineering Tools for Designing Enterprises. In: Bernus, P.; Nemes, L. (Eds.): Modelling and Methodologies for Enterprise Integration. To be published. 1996.

Buck-Emden, R.; Galimow, J.: Die Client/Server-Technologie des Systems R/3. 2. Auflage. Bonn et al. 1995.

Curtis, B.; Marc, I.K.; Over, J.: Process Modeling. Communications of the ACM. 35 (1992) 9.

Davenport, T. H.: Process Innovation. Reengineering Work Trough Information Technology. Boston 1993.

Detering, S.: Virtuelle Unternehmen: Technische, organisatorische, rechtliche und psychosoziale Voraussetzungen. Frankfurt 1995.

Doppler, K.; Lauterburg, C.: Change Management - Den Unternehmenswandel gestalten. Frankfurt/Main 1994.

Dürmeyer, K.: Informationsmodell - AD/Cycle. In: Scheer, A.-W. (Hrsg.): Handbuch Informationsmanagement: Aufgaben-Konzepte-Praxislösungen. Wiesbaden 1993, S. 143-172.

Grochla, E.: Einführung in die Organisationstheorie. Stuttgart 1978.

Hammer, M.; Champy, J.: Reengineering the Corporation. New York 1993.

Jorysz, HR; Vernadat, F.: CIMOSA Part I: Total Enterprise Modelling and Function View. In: International Journal of CIM, Vol. 3 / 41990.

Jorysz, HR; Vernadat, F.: CIMOSA Part II: Information View. In: International Journal of CIM, Vol. 3 / 4 1990.

Kagermann, H.: Client-Server-Modelle: Chancen oder Risiko für ein effektives Controlling. In: Management und Computer - Fachzeitschrift für EDV-orientierte Geschäftsprozesse. 1 (1993a) 4, S. 273-280.

Kagermann, H.: Verteilung integrierter Anwendungen. In: Wirtschaftsinformatik. 35 (1993b) 5, S. 455-464.

Keller, G.: Informationsmanagement in objektorientierten Organisationsstrukturen. Wiesbaden 1993.

Keller, G.: Creation of business processes with „,event-driven process chains (EPCs): A strategic challenge. In: SAP AG (Publisher): SAPinfo - Business Reengineering. Walldorf 1995a, S. 8-13.

Keller, G.: Eine einheitliche betriebswirtschaftliche Grundlage für das Business Reengineering. In: Brenner, W.; Keller, G. (Hrsg.): Business Reengineering mit Standardsoftware. Frankfurt-New York 1995b, S. 39-66.

Keller, G.; Meinhardt, S.: SAP R/3 Analyzer - Business Process Reengineering based on the R/3 Reference Model. Publisher: SAP AG. Walldorf 1994a.

Keller, G.; Meinhardt, S.: DV-gestützte Beratung bei der SAP-Softwareeinführung. In: HMD - Theorie und Praxis der Wirtschaftsinformatik. 31 (1994b) 174, S. 74-88.

Keller, G.; Nüttgens, M.; Scheer, A.-W.: Semantische Prozeßmodellierung auf der Grundlage „Ereignisgesteuerter Prozeßketten (EPK)“. In: Scheer, A.-W. (Hrsg.): Veröffentlichungen des Instituts für Wirtschaftsinformatik. Heft 89. Saarbrücken 1992.

Keller, G.; Popp, K.: Gestaltung von Geschäftsprozessen als betriebliche Aufgabe. In: Management und Computer - Fachzeitschrift für EDV-orientierte Geschäftsprozesse. 3 (1995) 1, S. 35-42.

Kosanke, K.; Klevers, T.: CIMOSA: Architecture for Enterprise Integration. Computer Integrated Manufacturing Systems, Vol.3, No 1, Feb. 1990.

Kosanke, K.: CIMOSA: Offene System Architektur. In: Scheer, A.-W. (Hrsg.): Handbuch Informationsmanagement: Aufgaben-Konzepte-Praxislösungen. Wiesbaden 1993, S. 113-141.

Meinhardt, S.: Eliminating outmoded structures and routines: Process-oriented implementation of R/3. In: SAP AG (Publisher): SAPinfo - Business Reengineering. Walldorf 1995a, S. 15-21.

Meinhardt, S.: Geschäftsprozeßorientierte Einführung von Standardsoftware. In: Wirtschaftsinformatik. 37 (1995b) 5 .

Meinhardt, S.; Teufel, T.: Business Reengineering im Rahmen einer prozeßorientierten Einführung der SAPStandardsoftware R/3. In: Brenner, W.; Keller, G. (Hrsg.): Business Reengineering mit Standardsoftware. Frankfurt-New York 1995, S. 69-94.

Nordsieck, F.: Die schaubildliche Erfassung und Untersuchung der Betriebsorganisation. Stuttgart 1932. 
Nüttgens, M.: Koordiniert-dezentrales Informationsmanagement: Rahmenkonzept-KoordinationsmodelleWerkzeug-Shell. Wiesbaden 1995.

Pentland, B.: Reliable Descriptions of Organizational Processes: Collecting Data for the Process Handbook. Los Angeles 1992.

Plattner, H.: Client/Server-Architekturen. In: Scheer, A.-W. (Hrsg.): Handbuch Informationsmanagement: Aufgaben-Konzepte-Praxislösungen. Wiesbaden 1993, S. 923-938.

Popp, K.: Business process design: Business process reengineering with the R/3 Reference Model. In: SAP AG (Publisher): SAPinfo - Business Reengineering. Walldorf 1995, S. 7-8.

SAP AG: The Plant Maintenance System. Functions in Detail. SAP AG, Walldorf/Baden March 1995.

Scheer, A.-W.: Architecture of Integrated Information Systems. Berlin et al. 1992.

Towers, S.: Business Process Reengineering. A Practical Handbook for Executives. Cheltenham 1994.

Williams, T.J.: Use of the Purdue Enterprise Reference Architecture and Methodolody in Industry. In: Bernus, P.; Nemes, L. (Eds.): Modelling and Methodologies for Enterprise Integration. To be published. 1996.

Zencke, P.: Softwareunterstützung im Business Process Reengineering. In: Schriften zur Unternehmensführung. Band 53. Wiesbaden 1994, S. 63-76.

\section{BIOGRAPHY}

Dr. Gerhard Keller is responsible for the R/3 Reference Model. He joined SAP in 1992. In a scientific cooperation project since $1990 \mathrm{Dr}$. Keller was in charge of developing a framework for process modeling. The EPC-methodology was designed in the course of this project by him.

Before joining SAP AG as Systems Analyst in 1994, Dipl. Inf. Sören Detering has studied Computer Science at the Technical University Berlin. His responsibilities include the development of process models for Plant Maintenance and Service Management applications. Research interests focus on Enterprise Modeling, Enterprise Integration and the Virtual Enterprise. 